\title{
Identifying challenges to enforcement in protected areas: empirical insights from 15 Colombian parks
}

Christoph NOLTE

\begin{abstract}
Protected areas are intended to conserve biodiversity by restricting human activities within their boundaries. However, such restrictions are difficult to enforce fully in many tropical parks. Improving regulatory enforcement requires an understanding of prevailing challenges to detection and sanctioning activities. Drawing from empirical field research in 15 Colombian parks, I show that current enforcement efforts may be insufficient to deter most priority threats. For long-term infractions, such as agriculture, livestock grazing, and construction, sanctioning violators is challenging, whereas for furtive infractions, such as logging and hunting, it may be difficult to detect violators. Investment in staff, equipment and infrastructure may fail to increase enforcement capacity and yield positive conservation outcomes unless accompanied by resolution of land tenure, clarification of use rights, improved patrolling strategies and protection of park guards.
\end{abstract}

Keywords Detection, deterrence, enforcement, illegal activities, land rights, parks, protected areas, regulation

\section{Introduction}

D rotected areas are the most widely used spatial policy instrument in efforts to conserve biological diversity. At $>175,000$ sites, covering an area twice the size of Brazil, there are spatially explicit regulations to protect species and ecosystems against anthropogenic pressures (Chape et al., 2005; Bertzky et al., 2012). There is evidence, however, that often people living near protected areas do not observe these regulations (Oates, 1999; Dudley et al., 2004; Terborgh, 2004) and that in many tropical protected areas enforcement is limited by budget constraints (Bruner et al., 2004; McCarthy et al., 2012). Improving the effectiveness of protected areas has thus become a key objective for the international nature conservation community (CBD \& UNEP, 2010; Coad et al., 2013), and international donors continue to dedicate billions of dollars to support tropical parks and reserves (GEF, 2009; Kasparek et al., 2010; Miller et al., 2013).

Christoph Nolte School of Natural Resources and Environment, University of Michigan, 440 Church Street, Ann Arbor, Michigan 48104, USA

E-mail cnolte@stanford.edu

Current address: School of Earth Sciences, Stanford University, 473 Via Ortega, Stanford, California 94305, USA

Received 14 April 2014. Revision requested 18 September 2014

Accepted 8 October 2014. First published online 6 February 2015.
Empirical analyses identify regulatory enforcement as a major determinant of the conservation success of parks (Bruner et al., 2001; Hilborn et al., 2006) and communitymanaged forests (Gibson et al., 2005; Chhatre \& Agrawal, 2008). However, enforcement in remote or inaccessible areas may be costly, and guards and other enforcement costs account for the bulk of annual budgets in many parks (Robinson et al., 2010). Analysts have thus begun to acknowledge that it is rarely optimal to prevent all illegal activity, redirecting analytical efforts instead to optimizing enforcement under existing budgetary constraints (Robinson et al., 2010; Albers \& Robinson, 2013).

Improving enforcement capacity in a protected area requires a comprehensive understanding of weaknesses in the prevailing enforcement regime. The presence of illegal activities suggests the benefits of these activities are perceived to outweigh the deterrents. To improve enforcement, decision makers must assess existing deterrents and identify where the weaknesses lie. Deterrents may be understood as the product of an enforcement chain of consecutive steps, such as detection, arrest, prosecution and conviction (Sutinen, 1987; Bruner et al., 2001; Akella \& Cannon, 2004). Weaknesses in any step can undermine the effectiveness of the enforcement regime. For instance, if sanctioning processes are ineffective, simply intensifying patrolling may be insufficient to increase deterrence. As most protected areas are exposed to various types of illegal activities (Leverington et al., 2010), with limited enforcement budgets to tackle these, the identification of weaknesses in enforcement requires a comprehensive assessment of all enforcement steps and priority threats within the protected areas.

I demonstrate the value of such a comprehensive approach through an empirical assessment of enforcement regimes in 15 Colombian parks. Second only to Brazil in terms of species richness (Groombridge \& Jenkins, 2002), Colombia has been ranked among the five countries with the highest potential to generate global biodiversity benefits (GEF, 2008). Colombia's system of national nature parks is representative of that of many developing countries rich in tropical biodiversity: parks cover extensive areas, and managers struggle to enforce regulations against diverse anthropogenic threats.

\section{Study area}

In 2013 the German government made a multi-million dollar commitment to improve the management and enforcement of parks in north-east Colombia. Assessing enforcement 
patterns prior to implementation was considered valuable for project implementation and future impact assessments. The main criterion for park selection for this study was therefore their inclusion among recipients of German funding: all but one park (Serranía De Los Yariguíes) were scheduled to receive additional enforcement resources from 2014 onwards (Fig. 1).

\section{Methods}

The research method was designed according to several application-oriented criteria. To be generalizable beyond the context of this study the method needed to demonstrate value across a variety of enforcement scenarios. The 15 parks selected (Fig. 1) vary in size $\left(6.4-3,830 \mathrm{~km}^{2}\right)$, altitude (o-c. $5,700 \mathrm{~m}$ ), accessibility, the range and intensity of threats, and the extent to which they overlap with historical land use, indigenous lands and private property. They span diverse ecosystems, including coral reefs, tropical beaches, saltwater and freshwater lagoons, mangrove forests, tropical rainforests, tropical dry forests, cloud forests, páramo, rock and ice.

To be applicable under conventional project conditions the method also needed to be cost-effective, producing reliable insights given a reasonable investment of time by the analyst and park staff. All data were collected through on-site workshops with key informants during SeptemberNovember 2013. At minimum, informants included the park manager, the staff member responsible for overseeing enforcement, and a senior park ranger with extensive experience in the area. In some cases the park manager invited all staff to attend the workshop. Depending on the complexity of the enforcement context, workshops were 2-6 hours in duration (mean 3 hours). Where possible, I accompanied park guards during routine patrols on the day prior to or following the workshop (10 of 15 parks). I did not interview other relevant people, such as rule violators.

To be suitable for project evaluation the method emphasized indicators that could be verified and tracked over time, wherever possible. Rather than using ratings or rankings, data collection was based predominantly on observable incidences of detection and sanctioning. Whenever indicator values were unobservable and had to be estimated by participants, observable supporting evidence was collected prior to the moment of estimation. For instance, before asking respondents to estimate the extent of a given threat (detected or undetected), I elicited supporting evidence on the spatiotemporal patterns of patrols, the estimated duration of an infraction, and the number of detected incidences. This approach of collecting less controversial and more easily verifiable indicators early in the workshop and using them to cross-check the plausibility of later estimates also served as a strategy to control potential strategic bias. For instance, staff might have under-reported enforcement success to

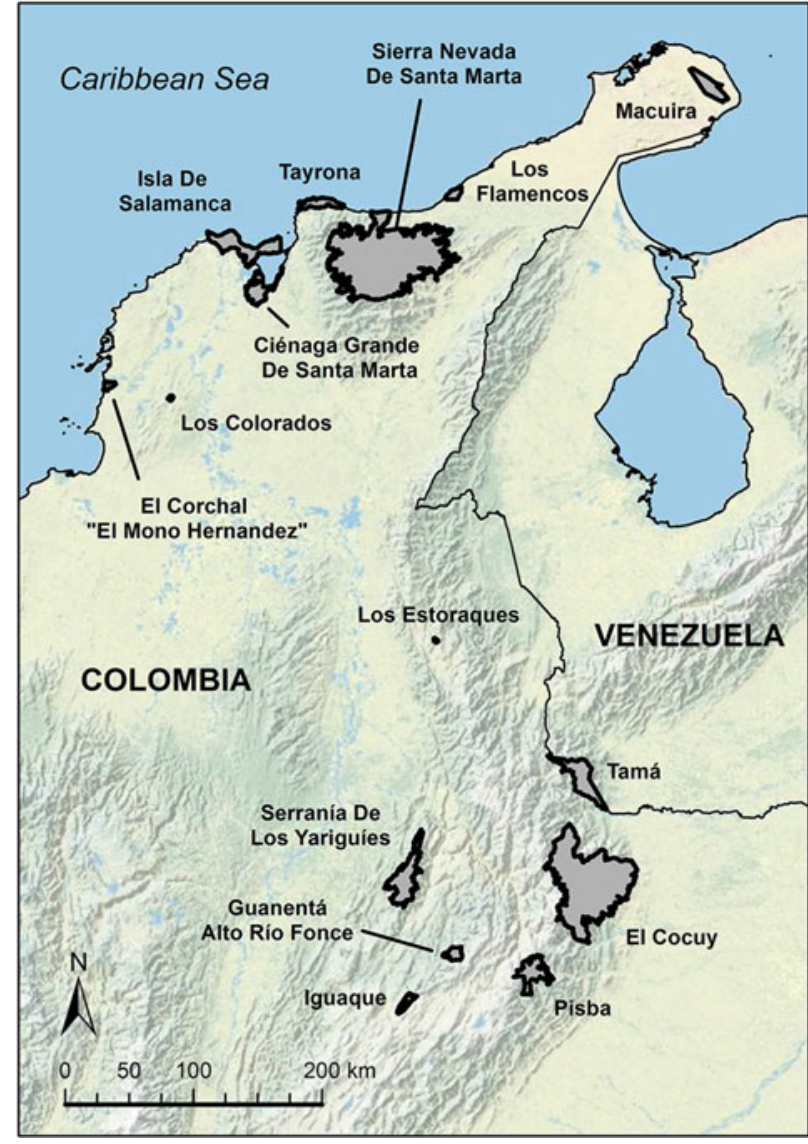

FIG. 1 Locations of the 15 national parks in Colombia included in this study.

signal greater need for resources, or over-reported success to suggest enhanced management capabilities. To minimize recall bias the method was applied to the 3 -year period prior to the workshop. In most parks few incidences of illegal activity had been detected and informants had little difficulty recalling specific enforcement events and their proceedings. If the number of detected incidences was high (e.g. Park Tayrona), supplementary information was obtained from lawyers in the regional park office.

At the beginning of each workshop I collected data on the park's enforcement resources (staff, equipment and infrastructure), patrolling intensity, patrolling patterns (including spatial and temporal predictability), and land tenure situation (private tenure claims and overlap with indigenous lands). I then asked participants to list all priority threats (i.e. illegal activities that occurred within the area, were perceived as a significant threat to conservation values, and fell within the park's enforcement mandate). Threats caused by human activities outside the park boundaries (e.g. climate change, siltation) or subject to high-level political decisions (e.g. major mining or infrastructure projects) were not included in this definition.

To estimate the magnitude of the deterrence for a given threat, participants were first asked to define a unit of 
infraction (e.g. logged trees, fishing trips). This was then used to quantify the number of incidences detected, estimated total incidences, arrests, convictions and sanctions (e.g. fines, value of confiscated goods). Following data collection I computed the deterrence as the total cost of observed sanctions divided by the estimated number of incidences (Sutinen, 1987; Akella \& Cannon, 2004). I then asked participants to estimate the size of this deterrence relative to the benefits expected from a single infraction, eliciting this estimate as an ordinal variable with five categories (Table 1). If deterrence was estimated to be zero (as in the majority of cases) this step did not require much thought. However, whenever estimated deterrence was $>$ o we relied on the knowledge and cognitive models of respondents regarding the economics of the illegal activity and the relevant benefits (material or non-material) for violators. Most groups were able to select indicator values without much disagreement. Subsequent discussions gave participants the opportunity to elaborate on reasons for the effectiveness or ineffectiveness of each step of the enforcement chain, and to suggest solutions.

Following field research I used a simple hierarchical categorization scheme to identify key challenges to enforcement. A priority threat was defined as posing a detection challenge if park staff estimated the empirical probability of detecting infractions and identifying the violator to be $<1 \%$. Priority threats without a detection challenge were categorized as posing a sanctioning challenge if $<1 \%$ of all violators identified had been sanctioned through fines, arrest, confiscation, demolition of property, or otherwise. Although this simple categorization could mask more complex enforcement processes (such as confiscating valuable equipment to incite self-denunciation), it proved useful for summarizing key enforcement challenges across diverse threats and parks.

\section{Results}

Interviewed park staff reported 1-6 categories of priority threats within their protected area, with a total of 54 individual priority threats reported (mean 3.6 threats per park). Threats linked to agricultural, pastoral and extractive resource uses were mentioned most frequently $(80 \%$; Table 1). Other priority threats included construction, tourism activity, and fires.

Respondents estimated most of their enforcement activity created only weak deterrence. For $47(87 \%)$ individual priority threats, park staff stated that deterrence was 'very low' (i.e. $<1 \%$ of the estimated expected benefits) for infractions committed within the previous 3 years (Table 1). For three other priority threats deterrence was estimated to be low (1-10\% of estimated benefits). Only two parks, Isla de Salamanca and Los Colorados, reported high deterrence (50-100\% of estimated benefits) for a given threat. At Isla de Salamanca the local police and army supported park staff in deterring illegal charcoal production, with confiscation of boats, minimum 3-day detention in prison, and criminal trials, and Los Colorados reported daily patrols to a roadside settlement within the park boundaries to halt new construction.

Challenges to enforcement were approximately equally distributed between priority threats: of 50 threats with low deterrence, $22(44 \%)$ posed detection challenges and 28 (56\%) posed sanctioning challenges. The distribution of challenges to enforcement indicates threat-specific patterns (Table 1): furtive infractions, such as logging, hunting, extraction of flora and fauna, and fires, were more likely to pose detection challenges. In contrast, infractions where the violator or his possessions had a permanent presence in the park, such as agriculture, construction and livestock grazing (especially within fenced areas), were more likely to pose sanctioning challenges. Illegal fishing in bogs, lagoons and coastal areas was reportedly more easily detectable than other furtive threats (with the exception of rare dynamite fishing) but nonetheless posed sanctioning challenges.

Workshop participants generally attributed low rates of sanctioning to the absence of an unambiguous legal framework recognized by all agencies responsible for enforcement, especially regarding land tenure. The majority of parks assessed (13 of 15 ) contained areas where private (and non-indigenous) stakeholders claimed ownership of the land. These included properties predating establishment of the park, as well as more recent settlements of refugees, armed groups or wealthy second-home owners. Claims were often reinforced through agricultural, pastoral or residential use. Five parks overlapped with indigenous reservations, the inhabitants of which were considered legally immune from park regulations, both within and outside reservation boundaries. Sanctioning of illegal fishing (four parks) suffered from the absence of a clear, official and operational distinction between legal subsistence fishing and other types of fishing; enforcement tended to focus on small subsets of illegal fishing where the distinction was clearest (e.g. spearfishing and angling in Tayrona) or where local extinction was imminent (e.g. clam fishing in Isla de Salamanca). Restrictions on tourist access were reportedly enforced only in parks where the carrying capacity had been estimated, and implemented by monitoring visitor frequency.

Challenges to detection were mostly associated with furtive activities (i.e. those requiring only a short period $\left(<_{1}\right.$ day) of detectable illegal activity in the field to generate benefits to violators; Table 1). For logging and hunting, even parks with high patrolling density (e.g. Tayrona, Los Colorados) had an estimated detection success of $<1 \%$. Ten parks $(67 \%)$ contained areas that had not been visited by guards for years, primarily because of limited accessibility; in six, such areas accounted for at least $50 \%$ of the territory. Furthermore, patrolling patterns in most parks enabled violators to adapt 
TABLE 1 Priority threats and corresponding deterrents identified in 15 national parks in Colombia (Fig. 1), with the level of deterrence, and detection and sanctioning challenges identified.

\begin{tabular}{|c|c|c|c|c|c|c|}
\hline \multicolumn{5}{|c|}{ evel of deterrence ${ }^{1}$ across parks } & \multirow{2}{*}{ 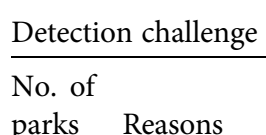 } & \multirow{2}{*}{$\begin{array}{l}\text { Sanctioning challenge } \\
\begin{array}{l}\text { No. of } \\
\text { parks Reasons }\end{array}\end{array}$} \\
\hline $\begin{array}{l}\text { Very low } \\
(<1 \%)\end{array}$ & $\begin{array}{l}\text { Low (1- } \\
10 \%)\end{array}$ & $\begin{array}{l}\text { Medium } \\
(10-50 \%)\end{array}$ & $\begin{array}{l}\text { High (50- } \\
100 \%)\end{array}$ & $\begin{array}{l}\text { Very high } \\
(>100 \%)\end{array}$ & & \\
\hline
\end{tabular}

\section{Livestock grazing}

Mostly cattle, also sheep, goats, donkeys, horses; within \& outside fenced properties

$\begin{array}{llllllll}11 & 0 & 1 & 0 & 0 & 4 & \text { No municipal retention facility for livestock, } 7\end{array}$ livestock not branded, absence of patrols in affected area

Unresolved land tenure (private \& collective), overlap with indigenous lands, conflict potential, slow legal

\section{Logging \& timber extraction}

processes

Selective extraction; pole cutting for fences; firewood collection; charcoal production

$\begin{array}{lllllll}6 & 2 & 0 & 1 & 0 & 6 & \text { Furtive activity, avoidance behaviour }\end{array}$

Agriculture (established)

Agricultural production on permanent plots; mostly small-scale farms, rarely larger plantations

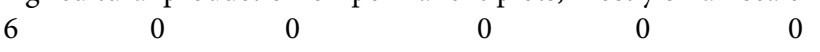

\section{Agricultural frontier expansion}

Slash-\&-burn cultivation of new or overgrown plots, mostly small-scale

$\begin{array}{lllllll}6 & 0 & 0 & 0 & 0 & 2 & \text { Furtive activity }\end{array}$

\section{Hunting, extraction of fauna/flora}

Hunting \& trapping for recreational, commercial \& subsistence purposes; collection of non-timber forest products $\begin{array}{lllllll}6 & 0 & 0 & 0 & 0 & 6 & \text { Furtive activity, avoidance behaviour }\end{array}$

Construction

Construction or improvement of family dwellings \& tourism infrastructure; second homes

$\begin{array}{llllll}2 & 1 & 1 & 1 & 0 & 0\end{array}$

\section{Tourism}

Unauthorized access \& camping; campfires; motorized access; entry of horses \& pets; rubbish disposal

$\begin{array}{lllllll}4 & 0 & 0 & 0 & 0 & 2 & \text { Furtive activity }\end{array}$

\section{Fishing}

ing (shellfish); rarely dynam

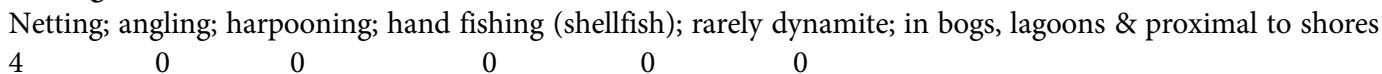
0
0

Fire

Mostly uncontrolled fires of hunters, tourists or farmers (campfires, smoking, slash-\&-burn)

Overlap with indigenous lands, high conflict potentia (including armed groups)

$6 \quad$ Unresolved land tenure (private), overlap with indigenous lands

$4 \quad$ Unresolved land tenure (private), overlap with indigenous lands, conflict potential (including armed groups)

Unresolved land tenure (private), overlap with indigenous lands, leniency towards repairs, demolitions are rare

Carrying capacity has not been defined

Difference between (legal) subsistence and (illegal) commercial/sport fishing has not been operationalized

$\begin{array}{llllllll}2 & 0 & 0 & 0 & 0 & 2 & \text { Furtive activity } & 0\end{array}$

${ }^{1}$ Relative to benefit expected from a single infraction.

${ }^{2}$ Ecotourism developments were often estimated to generate significant income despite on-going sanctioning processes. 
furtive activities to avoid detection. Guards did not patrol regularly outside daylight hours, with the exception of nocturnal monitoring of turtle nests on the beaches of Tayrona and Sierra Nevada de Santa Marta. Only four parks scheduled patrols on weekends and many reported evidence of higher infraction frequency during these days. Livestock grazing posed detection challenges in several parks where grazing animals were unmarked and could not be confiscated because of the lack of adequate municipal detention facilities.

Respondents referred to the potential of enforcement to cause conflict as an explanatory factor for low detection and sanctioning rates. In 12 parks (80\%) staff reported specific incidences of risk to their well-being resulting from enforcement in the recent past, including verbal aggression, ostracism, damage to park equipment (punctured tyres of park vehicles, stolen signposts, destruction of cabins), and threats of physical aggression (including with machetes, fishing dynamite, and firearms). Assassinations of park employees, although infrequent, had occurred until the early 200os, and seven parks reported the presence of armed groups within and around their territory. Park guards reported occasionally avoiding high-conflict tasks, such as the formal identification of violators, confiscations and the initiation of sanctioning processes, to reduce the risk of retaliatory actions. They also reported refraining from obligatory sanctioning if violators were poor or displaced, or had been living in or next to the park for a long time. Spatial strategies for conflict avoidance were reported rarely, and most guards reported patrolling high-conflict areas with higher frequency.

\section{Discussion}

Protected-area regulations are believed to contribute to conserving biodiversity when there are mechanisms in place to ensure regulatory compliance. Deterrence through enforcement is often considered such a mechanism but it seems unlikely to contribute significantly to the reduction of priority threats in the Colombian parks studied. According to park employees, deterrence was generally weak and unlikely to make a significant difference in the decision making of violators. However, weak deterrence does not preclude the possible existence of other mechanisms for reducing threats. There is evidence that individuals can be influenced to conform to formal rules or moral standards without the need for formal enforcement and economic sanctions, for example through moral suasion (Cialdini et al., 2006; Stern, 2008; Ferraro \& Price, 2013). This study did not examine threats that may have existed prior to the assessed time period but were removed by successful enforcement. However, the presence and persistence of detectable illegal activities supports the evidence for limitations to enforcement, and many park staff acknowledged and expressed frustration over the weaknesses in the prevailing enforcement regime.
Increasing the enforcement capacity of the parks studied would probably require more than investment in guards, equipment and infrastructure. The results of this study suggest a number of potential pathways. The resolution of land tenure conflicts may be a precondition for improved regulatory compliance, as also indicated by insights from 66 protected areas in the neighbouring Brazilian Amazon (Nolte et al., 2013). Effective detection and sanctioning in the threat categories of fishing and tourism seems to depend on legally consistent and operational distinctions between permitted and sanctioned activities. Detection probabilities for furtive activities such as hunting and logging are unlikely to increase as long as predictability of the timing and location of patrols allows violators to engage in simple and inexpensive avoidance strategies. Finally, efforts to increase enforcement capacity in the parks may fall short of expectations if they do not incorporate strategies to protect park guards from perceived risks of retaliation.

Incorporating multiple threats, parks and enforcement steps in a single empirical analysis was helpful to identify these major patterns in enforcement. However, several limitations arise from the use of cross-sectional enforcement data. Firstly, challenges in early enforcement steps (e.g. low detection rates) can impede the observation of potential challenges in later steps (e.g. sanctioning). Secondly, potential interactions between enforcement challenges may distort overall findings. For instance, the anticipation of potential conflict or slow legal processes could undermine the enthusiasm of park guards to detect or report infractions. However, the magnitude of this effect remains largely indeterminable.

The identification of core challenges to enforcement is a first step towards improving regulatory compliance in tropical parks. Improving the cost-effectiveness of enforcement, however, requires not only insights into the existence and importance of such challenges but also on the estimated or actual cost-effectiveness of interventions to resolve them. Research into the costs and impacts of resolving land tenure, improving patrolling strategies, and protecting the well-being of park guards, among other things, would be valuable for the design of better enforcement strategies in Colombia and in other tropical countries.

\section{Acknowledgements}

I thank Parques Nacionales Naturales de Colombia for the excellent collaboration throughout the field research period. Arun Agrawal, Paul Ferraro, Kobe de Pourq, Gustavo Kattan and an anonymous reviewer provided helpful comments. The research was supported by grants from the Gordon and Betty Moore Foundation (\#3006) and the National Science Foundation (BCS 1333279). 


\section{References}

Akella, A.S. \& Cannon, J.B. (2004) Strengthening the Weakest Links: Strategies for Improving the Enforcement of Environmental Laws Globally. Conservation International, Washington, DC, USA.

Albers, H.J. \& Robinson, E.J.Z. (2013) A review of the spatial economics of non-timber forest product extraction: implications for policy. Ecological Economics, 92, 87-95.

Bertzky, B., Corrigan, C., Kemsey, J., Kenney, S., Ravilious, C., Besançon, C. \& Burgess, N. (2012) Protected Planet Report 2012: Tracking Progress Towards Global Targets for Protected Areas. IUCN, Gland, Switzerland, and UNEP-WCMC, Cambridge, UK.

Bruner, A.G., Gullison, R.E. \& Balmford, A. (2004) Financial costs and shortfalls of managing and expanding protected-area systems in developing countries. BioScience, 54, 1119-1126.

Bruner, A.G., Gullison, R.E., Rice, R.E. \& da Fonseca, G.A.B. (2001) Effectiveness of parks in protecting tropical biodiversity. Science, 291, 125-128.

CBD \& UNEP (Convention on Biological Diversity \& United Nations Environment Programme) (2010) Strategic Plan for Biodiversity 2011-2020. Secretariat of the Convention on Biological Diversity, Montreal, Canada.

Chape, S., Harrison, J., Spalding, M. \& Lysenko, I. (2005) Measuring the extent and effectiveness of protected areas as an indicator for meeting global biodiversity targets. Philosophical Transactions of the Royal Society of London B, 360, 443-455.

Chhatre, A. \& Agrawal, A. (2008) Forest commons and local enforcement. Proceedings of the National Academy of Sciences of the USA, 105, 13286-13291.

Cialdini, R.B., Demaine, L.J., Sagarin, B.J., Barrett, D.W., Rhoads, K. \& Winter, P.L. (2006) Managing social norms for persuasive impact. Social Influence, 1, 3-15.

Coad, L., Leverington, F., Burgess, N.D., Cuadros, I.C., Geldmann, J., Marthews, T.R. et al. (2013) Progress towards the CBD protected area management effectiveness targets. PARKS, 19.1, $1-125$.

Dudley, N., Belokurov, A., Borodin, O., Higgins-Zogib, L., Hockings, M., Lacerda, L. \& Stolton, S. (2004) How Effective are Protected Areas? A Preliminary Analysis of Forest Protected Areas by WWF-the Largest Ever Global Assessment of Protected Area Management Effectiveness. WWF, Gland, Switzerland.

Ferraro, P.J. \& Price, M.K. (2013) Using nonpecuniary strategies to influence behavior: evidence from a large-scale field experiment. The Review of Economics and Statistics., 95, 64-73.

GEF (Global Environment Facility) (2008) GEF Benefits Index (GBI) for Biodiversity: Initial and Revised July 2008. Global Environment Facility, Washington, DC, USA.

GEF (Global Environment Facility) (2009) GEF Focal Area: Biodiversity. Global Environment Facility, Washington, DC, USA.
Gibson, C.C., Williams, J.T. \& Ostrom, E. (2005) Local enforcement and better forests. World Development, 33, 273-284.

Groombridge, B. \& Jenkins, M.D. (2002) World Atlas of Biodiversity. University of California Press, Berkeley, USA.

Hilborn, R., Arcese, P., Borner, M., Hando, J., Hopcraft, G., Lогвоокі, M. et al. (2006) Effective enforcement in a conservation area. Science, 314, 1266.

Kasparek, M., Mack, R., Mayer, C. \& Riha, K. (2010) Biodiversity in German Development Cooperation 2010. Deutsche Gesellschaft für Technische Zusammenarbeit (GTZ) GmbH, Eschborn, Germany.

Leverington, F., Costa, K.L., Courrau, J., Pavese, H., Nolte, C., Marr, M. et al. (2010) Management Effectiveness Evaluation in Protected Areas-a Global Study. Second Edition 2010. University of Queensland, Brisbane, Australia.

McCarthy, D.P., Donald, P.F., Scharlemann, J.P.W., Buchanan, G.M., Balmford, A., Green, J.M.H. et al. (2012) Financial costs of meeting global biodiversity conservation targets: current spending and unmet needs. Science, 338, 946-949.

Miller, D.C., Agrawal, A. \& Roberts, J.T. (2013) Biodiversity, governance, and the allocation of international aid for conservation. Conservation Letters, 6, 12-20.

Nolte, C., Agrawal, A. \& Barreto, P. (2013) Setting priorities to avoid deforestation in Amazon protected areas: are we choosing the right indicators? Environmental Research Letters, 8, 1-7.

OAtes, J.F. (1999) Myth and Reality in the Rain Forest: How Conservation Strategies are Failing in West Africa. University of California Press, Berkeley, USA.

Robinson, E.J.Z., Kumar, A.M. \& Albers, H.J. (2010) Protecting developing countries' forests: enforcement in theory and practice. Journal of Natural Resources Policy Research, 2, 25-38.

STERN, M.J. (2008) Coercion, voluntary compliance and protest: the role of trust and legitimacy in combating local opposition to protected areas. Environmental Conservation, 35, 200-210.

Sutinen, J.G. (1987) Enforcement of the MFCMA : an economist's perspective. Marine Fisheries Review, 49, 36-43.

Terborgh, J.W. (2004) Requiem for Nature. Island Press, Washington, DC, USA.

\section{Biographical sketch}

Christoph Nolte is enthusiastic about the empirical evaluation of the impact of conservation policies and programmes. His work combines econometrics, remote sensing and qualitative research methods. He has researched eco-labelling in Jordan, watershed payments in China, protected area management indicators in Europe and, more recently, the governance and management of hundreds of protected areas in Brazil and Colombia, and their effectiveness in avoiding deforestation and forest fires. 